\title{
AVALIAÇÃO DO POTENCIAL DE DESENVOLVIMENTO DE FUTUROS LABORA- TÓRIOS EXPERIMENTAIS COMO CÉLULAS DE CO-MANEJO NOS PONTOS DE CULTURA DO MUNCÍPIO DE SANTOS - SP
}

\author{
MAIRA BEgALLI* \\ *Pesquisa experimentações tecnológicas e ecológicas colaborativas. Mestranda do programa de \\ pós-graduação em Sustentabilidade de Ecossistemas Costeiros e Marinhos da Universidade Santa Cecília \\ (ECOMAR/ UNISANTA). ce0064@gmail.com (autora para correspondência) \\ MiLena RAMIREs** \\ **Doutora pelo programa Interdisciplinar em Ambiente e Sociedade pela UNICAMP (2008), docente do \\ programa de pós-graduação ECOMAR/ UNISANTA . milena.ramires@hotmail.com

\section{MARIANA Clauzet***} \\ ***Doutora pelo programa Interdisciplinar em Ambiente e Sociedade pela UNICAMP (2008), docente do \\ programa de pós-graduação ECOMAR/ UNISANTA . mariana.clauzet@gmail.com
}

\section{RESUMO}

O presente trabalho identifica e a avalia os Pontos de Cultura existentes na cidade de Santos-SP, com o objetivo de detectar possibilidades para futuros desenvolvimentos de laboratórios experimentais como núcleos de co-manejo. A pesquisa, que usou como base o Catálogo da Rede dos Pontos de Cultura do Estado de São Paulo para a identificação dos Pontos (BRASIL, 2012), foi realizada entre os meses de junho e julho de 2012. Foram identificados dois Pontos de Cultura: o Projeto Parcel, localizado na área continental de Santos, e a Estação da Cidadania e Cultura, na área insular de Santos. Ambos possuem potencial para o desenvolvimento de atividades experimentais relacionadas à temática e poderiam subsidiar atividades de co-manejo.

Palavras-chave: ecologia humana, tecnologias experimentais, co-manejo, Santos, Pontos de Cultura. 


\title{
EVALUATION OF POTENTIAL FUTURE DEVELOPMENT OF EXPERIMENTAL LA- BORATORY HOW CELLS CO-MANAGEMENT IN POINTS OF CULTURE MUNICIPIO SANTOS - SP
}

\begin{abstract}
This paper identifies and evaluates the Points of Culture in the city of Santos, São Paulo State, aiming to detect possibilities for future developments of experimental laboratories as nuclei for co-management. The survey, which used as source the $\mathrm{Ne}-$ twork Catalog of Culture Points of São Paulo State to identify points (BRAZIL 2012), was carried out between June and July 2012. It was identified two Points of Culture: the "Project Parcel", located in the continental area, and the "Station of Citizenship and Culture", in the insular area of Santos. Both have potential to develop experimental activities related to the theme and could subsidize activities of co-management.
\end{abstract}

Keywords: human ecology; experimental technologies; co-management; Santos; Culture Points

\section{INTRODUÇÃO}

O uso e a apropriação de tecnologias proporcionaram mudanças significativas para as populações humanas. Há cerca de 500 mil anos, o uso do fogo para a preparação de alimentos tornou possível a utilização de alguns vegetais, que de outra forma não seriam comestíveis (KORMONDY \& BROWN, 2002). As antigas técnicas de irrigação em ambientes áridos possibilitaram a edificação de sociedades hidráulicas, como a Mesopotâmia (BEGOSSI, 1993). O desenvolvimento de projetos que agregam a apropriação crítica de tecnologias às ciências ambientais está proporcionando uma abordagem mais ampla em relação aos usos e impactos de manipulações biológicas nos ecossistemas.

Os chamados "fabricantes de biologias pessoais" executam propostas de biotecnologia em pequena escala, como um processo artesanal que pode ser produzido e compreendido por meio de documentação e trocas compartilhadas em rede (WOHLSEN, 2011). 
Ao contrário do deslumbramento tecnológico e da cultura do consumo baseada na obsolescência das rápidas inovações do mercado, tais práticas estão fomentando processos experimentais e formas de empoderamento para muitos indivíduos (HAND, 2010).

Buscando atrelar a apropriação crítica de tecnologias aos saberes de populações humanas foi instituída a proposta dos Pontos de Cultura pelo "autoproclamado" ministro hacker Gilberto Gil (2003-2008), por meio das portarias no 156, de 06 de julho de 2004 (Brasil, 2004), e $n^{\circ}$ 82, de 18 de maio de 2005 (BRASIL, 2005) do Ministério da Cultura (MinC), que validou o Programa Nacional de Cultura, Educação e Cidadania: Cultura Viva. O Cultura Viva formalizou-se ao promover editais, prêmios e bolsas para o repasse de recursos públicos a pessoas físicas e jurídicas (TURINO, 2009). No caso dos Pontos de Cultura, a seleção ocorre por meio de editais das Redes de Pontos de Culturas estaduais e municipais que selecionam projetos enviados por entidades privadas sem fins lucrativos (OrganizaçãoNão Governamental - ONG, Associação, Cooperativa ou Organização da Sociedade Civil de Interesse Público - OSCIP).

No ínicio da década de 2000, de forma descentralizada e autônoma surgiram alguns laboratórios experimentais que passaram a trabalhar com elementos eletrôrganicos, ou seja, orgânicos (biodiversidade local) e eletrônicos (apropriação crítica de tecnologias, hardware e softwares livres e lixo eletrônico), como soluções criativas colaborativas e do faça-você-mesmo (do it yourself - DIY) aplicáveis no manejo colaborativo de suas regiões (FONSECA, 2012). É possível citar como exemplos bem sucedidos de laboratórios experimentais que desenvolvem ações de co-manejo o UbaLab ${ }^{1}$, localizado em Ubatuba, São Paulo, e a Nuvem - Estação Rural de Arte e Tecnologia² sediada no Vale do Pavão, em Visconde de Mauá. Tratam-se de núcleos que agregam em seus projetos transversais de meio ambiente, sociedade e tecnologias, diferentes atores sociais que negociam para definir e garantir, entre si, direitos e responsabilidades para a gestão dos recursos socioambientais das localidades em que se encontram (GUITIÉRREZ et al., 2011).

O objetivo desse trabalho consiste na identificação dos Pontos de Cultura sediados no município de Santos-SP, para avaliar o potencial de desenvolvimento de futuros laboratórios experimentais como células de co-manejo, em uma cidade que passa

\footnotetext{
${ }^{1}$ Mais informações em http://ubalab.org/sobre

${ }^{2}$ Mais informações em http://nuvem.tk/?espa\%C3\%A7o-conceito
} 
por processos socioambientais conflitantes, como: a verticalização exacerbada, a especulação acerca do pré-sal, a erosão costeira, os impactos gerados pelo Porto, a supressão de fauna e flora, entre outros (AFONSO, 1999).

\section{MATERIAIS E MÉTODOS}

A metodologia consistiu no levantamento de dados bibliográficos sobre os Pontos de Cultura existentes na cidade de Santos, por meio da base de dados do Catálogo da Rede dos Pontos de Cultura do Estado de São Paulo (BRASIL, 2012), e posteriormente, na visita aos Pontos listados por meio de observação direta, registros fotográficos e entrevistas (com questões abertas) entre os dias 10 e 12 de julho de 2012 (VIETLER, 2002). As visitas aos Pontos de Cultura foram agendadas por meio de contato telefônico com os seus respectivos gestores, entre os dias 18 e 19 de junho de 2012. Para avaliação dos Pontos foi elaborado um questionário contendo critérios objetivos, com escala de pontuação de 1 a 3 (sendo 1 a pontuação mínima, e 3 a máxima). Ressalvas sobre outros fatores percebidos, mas não relatados para pontuação também foram agregados à coleta de dados.

\section{RESULTADOS E DISCUSSÃO}

O Catálogo da Rede dos Pontos de Cultura do Estado de São Paulo indicou 4 Pontos de Cultura na cidade de Santos, porém, um deles foi desconsiderado: o Azimuth Ponto de Cultura e Sustentabilidade ${ }^{3}$, classificado como integrante da cidade de Santos porém encontrava-se geograficamente localizado no município de llhabela. Deste modo, restaram o Projeto Parcel ${ }^{4}$, localizado na área continental de Santos, o Vozes da Senzala ${ }^{5}$ e a Estação da Cidadania e Cultura ${ }^{6}$, ambos localizados na área insular de Santos (BRASIL, 2012).

\footnotetext{
${ }^{3}$ http://www.azimuth.org.br/

${ }^{4}$ http://www.parcel.org.br/

${ }^{5} \mathrm{http}: / /$ vozesdesenzalapontod.wix.com/vozesdesenzalapontodecultura\#!ecoam-as-vozes

${ }^{6}$ http://pontoestacaodacidadania.wordpress.com/
} 
A visita inicial à Estação da Cidadania e Cultura foi agendada para o dia 10 de julho de 2012 (terça-feira), às 19 horas. No Vozes da Senzala foi agendado um encontro na região central de Santos, no dia 11 de julho (quarta-feira), às 17 horas, pois a gestora do Ponto, informou que estavam sem uma sede fixa. No Projeto Parcel a data agendada foi o dia 12 de julho de 2012 (quinta-feira), às 14 horas. Contudo, a pesquisa não foi realizada com o Vozes da Senzala, pois o encontro agendado para o dia $11 \mathrm{de}$ julho de 2012, no centro de Santos, foi cancelado pela própria gestora. Posteriormente, tentou-se um contato via skype, sem retorno. Deste modo, optou-se por invalidar a possibilidade de realizar a pesquisa neste Ponto de Cultura.

Ao final da avaliação, ambos os Pontos apresentaram pontuação 19 (tabela 1). Entretanto, a diferença ocorreu nos itens: 2) Identificação com a temática e 5) Uso de software livre e formatos abertos. Apesar da receptividade do gestor da Estação da Cidadania, o mesmo afirmou que o desenvolvimento de um laboratório experimental talvez estivesse um pouco fora do escopo das atividades do Ponto, uma vez que a Estação da Cultura e Cidadânia possui muitas atividades e um público definido. Já no Projeto Parcel, a gestora afirmou que não existiam trabalhos e propostas ligadas a tecnologia e formatos digitais no Ponto de Cultura e que tinha interesse em desenvolver a proposta.

Tabela 1 - Avaliação dos Pontos de Cultura do Município de Santos

\begin{tabular}{|c|c|c|}
\hline $\begin{array}{l}\text { Ponto de Cultura } \\
\text { Critérios de Escolha }\end{array}$ & $\begin{array}{c}\text { Estação da Cidadania } \\
\text { e Cultura }\end{array}$ & Projeto Parcel \\
\hline 1. Receptividade da proposta & 3 & 3 \\
\hline 2. Identificação com a temática & 1 & 3 \\
\hline $\begin{array}{l}\text { 3. Disponibilidade para a } \\
\text { realização da proposta }\end{array}$ & 3 & 3 \\
\hline 4. Infraestrutura & 3 & 3 \\
\hline $\begin{array}{l}\text { 5. Uso de software livre e } \\
\text { formatos abertos }\end{array}$ & 3 & 1 \\
\hline $\begin{array}{l}\text { 6. Aderência com os interesses dos } \\
\text { participantes do Ponto } \\
\text { de Cultura }\end{array}$ & 3 & 3 \\
\hline $\begin{array}{l}\text { 7. Possibilidade de apropriação/ } \\
\text { continuidade }\end{array}$ & 3 & 3 \\
\hline TOTAL & 19 & 19 \\
\hline
\end{tabular}


O Ponto de Cultura Estação da Cidadania e Cultura encontra-se na área insular de Santos (figura 1), em perímetro urbano, a cerca de 200 metros do Canal 3 (um canal que realiza o escoamento de águas pluviais para o mar) localizado na Avenida Washington Luís. É constituído juridicamente como Organização Não Governamental (ONG), fundada em 2002.

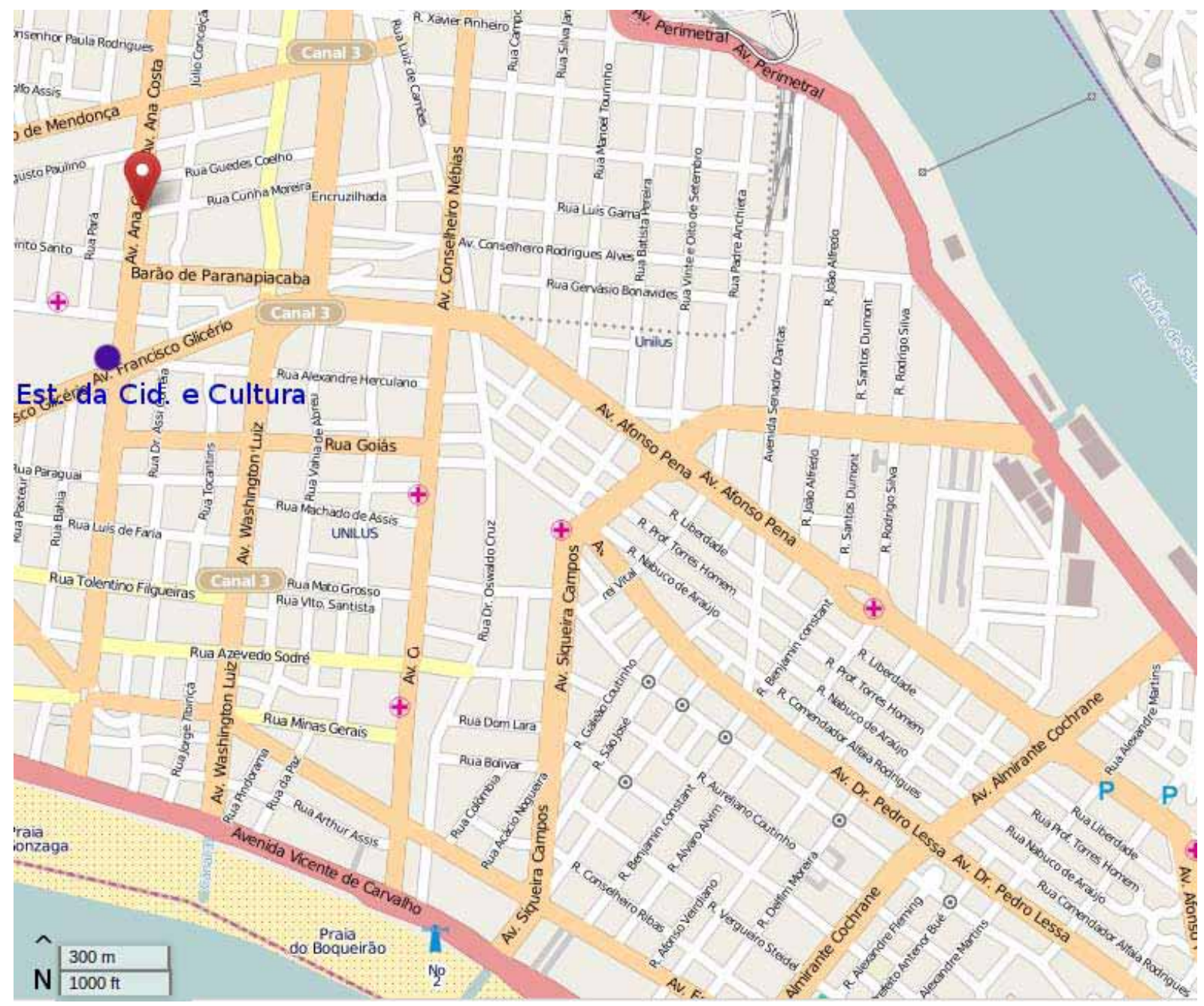

Figura 1 - Localização do Ponto Estação da Cidadania e Cultura (OPEN STREET MAP7, 2012).

\footnotetext{
${ }^{7}$ OpenStreetMap é uma iniciativa aberta para criar e fornecer dados e mapas geográficos. Mais informações em http://blog.osmfoundation.org/faq/
} 
O Ponto de Cultura Projeto Parcel localiza-se na área continental de Santos (figura 2), longe do perímetro urbano, próximo ao canal de Bertioga, e é constituído juridicamente como uma Associação, fundada em 2005.

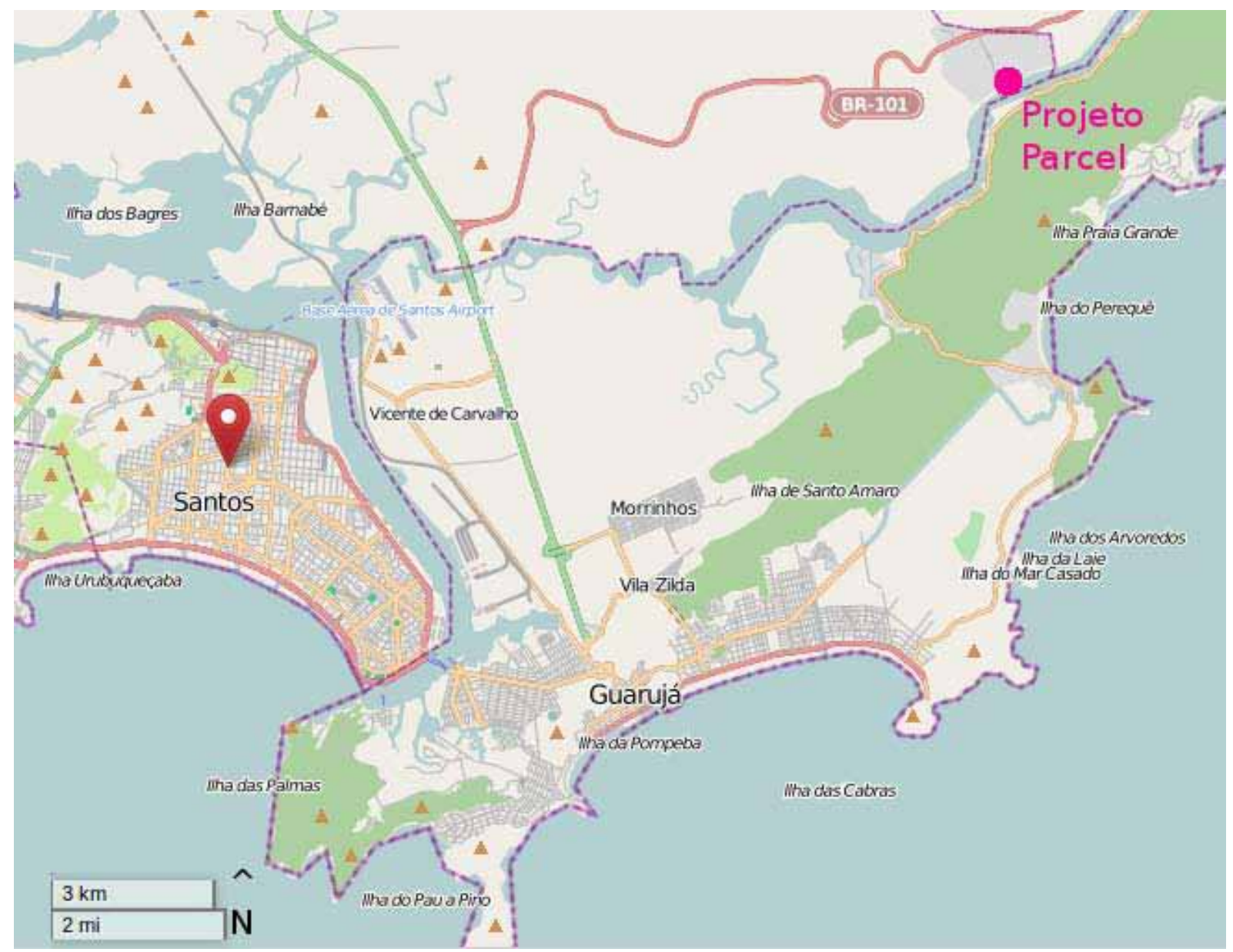

Figura 2 - Localização do Ponto Projeto Parcel (Open Street Map, 2012).

Segundo dados oficiais da Prefeitura Municipal de Santos, a extensão territorial da área continental é cerca de seis vezes maior, com 231,6 quilômetros quadrados, em contraponto aos 39,4 quilômetros quadrados da área insular. Destes, 206 quilômetros encontram-se sob a Área de Proteção Ambiental (APA), no Parque Estadual da Serra do Mar (SANTOS, 2012). A APA (tabela 2) foi instituída pela Lei Complementar do município de Santos de número 359, em 25 de novembro de 1999, que dispôs sobre o uso e a ocupação da região (SANTOS, 1999). 
Tabela 2 - Caracterização da Área de Proteção Ambiental da área continental de Santos

\begin{tabular}{|c|c|c|}
\hline \multicolumn{3}{|c|}{ Área de Proteção Ambiental / 206 km } \\
\hline Zonas & Usos e Características & Localidade/Bairro \\
\hline $\begin{array}{c}\text { Zona de Uso Especial } \\
\text { ZUE }\end{array}$ & $\begin{array}{l}\text { A ocupação e o aproveitamento em } \\
\text { conformidade com o Plano de Manejo } \\
\text { elaborado pelo Governo do Estado. }\end{array}$ & $\begin{array}{l}\text { Parque Estadual } \\
\text { da Serra do Mar }\end{array}$ \\
\hline $\begin{array}{c}\text { Zona de Preservação } \\
\text { ZP }\end{array}$ & \multirow{2}{*}{$\begin{array}{l}\text { - Taxa de ocupação máxima para os } \\
\text { usos permitidos é de } 5 \% \text {. } \\
\text { - Respeitar e manter áreas com valor } \\
\text { histórico-cultural como vestígios arque- } \\
\text { ológicos e arquitetônicos. } \\
\text { - A área mínima estabelecida para as } \\
\text { glebas é de } 40.000 \mathrm{~m}^{2} \text {. }\end{array}$} & $\begin{array}{l}\text { Áreas não descri- } \\
\text { tas por seus limites } \\
\text { nas demais zonas } \\
\text { que se encontram } \\
\text { na Área Continen- } \\
\text { tal de Santos }\end{array}$ \\
\hline $\begin{array}{c}\text { Zona de Conservação } \\
\text { ZC }\end{array}$ & & $\begin{array}{l}\text { Rio Quilombo, Rio } \\
\text { Jurubatuba, Monte } \\
\text { Cabrão, Trindade }\end{array}$ \\
\hline $\begin{array}{l}\text { Zona de Uso Agropecu- } \\
\text { ário ZUA }\end{array}$ & $\begin{array}{l}\text { Taxa de ocupação máxima para os usos } \\
\text { permitidos é de } 40 \% \text {. Sendo } 20.000 \mathrm{~m}^{2} \text { a } \\
\text { área mínima estabelecida para as glebas. }\end{array}$ & $\begin{array}{l}\text { Rio Quilombo, Ex- } \\
\text { tremo Setentrional }\end{array}$ \\
\hline
\end{tabular}

(Santos, 1999).

Os 25 quilômetros restantes foram classificados como Área de Expansão Urbana (tabela 3). Atualmente, a área continental agrega nove bairros: Barnabé, Cabuçu-Caetê, Caruara, Guarapá, Iriri, Monte Cabrão, Nossa Senhora das Neves, Quilombo e Trindade. Antes da Lei 359/99, a área encontrava-se dividida em três bairros: Ilha Diana, Caruara e Monte Cabrão (SANTOS, 1999). A porção da área continental destinada à APA encontra-se dividida em 4 zonas: Zona de Uso Especial (ZUE), Zona de Preservação (ZP), Zona de Conservação (ZC) e Zona de Uso Agropecuário (ZUA). Possui limitações restritivas acerca do uso dos recursos naturais e da ocupação territorial, e objetiva a preservação e conservação das localidades que envolvem os rios Quilombo e Jurubatuba, o extremo setentrional, os bairros de Trindade e Monte Cabrão, o Parque Estadual da Serra do Mar, além de áreas que não foram contempladas no dispositivo legal 359/99 (SANTOS, 1999). 
Tabela 3 - Caracterização da Área de Expansão Urbana da área continental de Santos

\begin{tabular}{|c|c|c|}
\hline \multicolumn{2}{|c|}{ Área de Expansão Urbana / 25km } \\
\hline $\begin{array}{c}\text { Zona Urbana } \\
\text { ZU }\end{array}$ & $\begin{array}{l}\text { Usos e Características } \\
\text { Desenvolvimento urbano, ocupação } \\
\text { ordenada e regularização das áreas } \\
\text { já consolidadas }\end{array}$ & $\begin{array}{l}\text { Guarapá, Monte Cabrão, } \\
\text { Trindade, Cabuçu, Iriri, } \\
\text { Caruara }\end{array}$ \\
\hline $\begin{array}{c}\text { Zona de Suporte } \\
\text { Urbano I } \\
\text { ZSU I }\end{array}$ & $\begin{array}{l}\text { Áreas degradadas, onde ocorrem ativida- } \\
\text { des extrativistas minerais, que possibili- } \\
\text { tam a disposição final de resíduos sólidos }\end{array}$ & $\begin{array}{l}\text { Bairros não } \\
\text { especificados }\end{array}$ \\
\hline $\begin{array}{c}\text { Zona de Suporte } \\
\text { Urbano II } \\
\text { ZSU II }\end{array}$ & $\begin{array}{l}\text { Áreas degradadas, onde ocorrem ativida- } \\
\text { des extrativistas minerais e que possibili- } \\
\text { tam atividades de interesse para o desen- } \\
\text { volvimento turístico }\end{array}$ & $\begin{array}{l}\text { Guarapá, Jurubatuba, } \\
\text { Trindade }\end{array}$ \\
\hline $\begin{array}{c}\text { Zona Portuária } \\
\text { e Retroportuária } \\
\text { ZPR }\end{array}$ & $\begin{array}{l}\text { Áreas potenciais para instalações rodovi- } \\
\text { árias, ferroviárias, portuárias, retroportuá- } \\
\text { rias e ligadas às atividades náuticas. }\end{array}$ & $\begin{array}{l}\text { Quilombo, Sítio das } \\
\text { Neves llha Barnabé } \\
\text { (oeste e leste) }\end{array}$ \\
\hline
\end{tabular}

(Santos, 1999).

A Área de Expansão Urbana caracteriza-se por espaços territoriais em que o ecossistema original sofreu grandes modificações devido à forte influência antrópica ocorrida por meio de ocupações desordenadas, extrativismo, disposição de resíduos sólidos, turismo e atividades náuticas, assim como instalações portuárias e retroportuárias, ferroviárias e rodoviárias. Encontra-se dividida em 4 zonas: Zona Urbana (ZU), Zona de Suporte Urbano I (ZSUI) e II (ZSUII), Zona Portuária e Retroportuária (ZPR), entretanto, são parcelas de menores extensões quando comparadas às zonas da APA (SANTOS, 2012).

A sede do Ponto de Cultura Estação da Cidadania e Cultura pertence ao Grupo Pão de Açúcar, que concedeu comodato por período indeterminado à ONG. Trata-se de um ponto histórico relevante, pois no local funcionava a Estação Ferroviária Sorocabana, que fazia o trajeto Santos-Mairinque (figura 3). Possui fácil acesso aos transportes públicos, os fundos do Ponto de Cultura levam ao estacionamento do supermercado Extra, localizado na Avenida Ana Costa. 


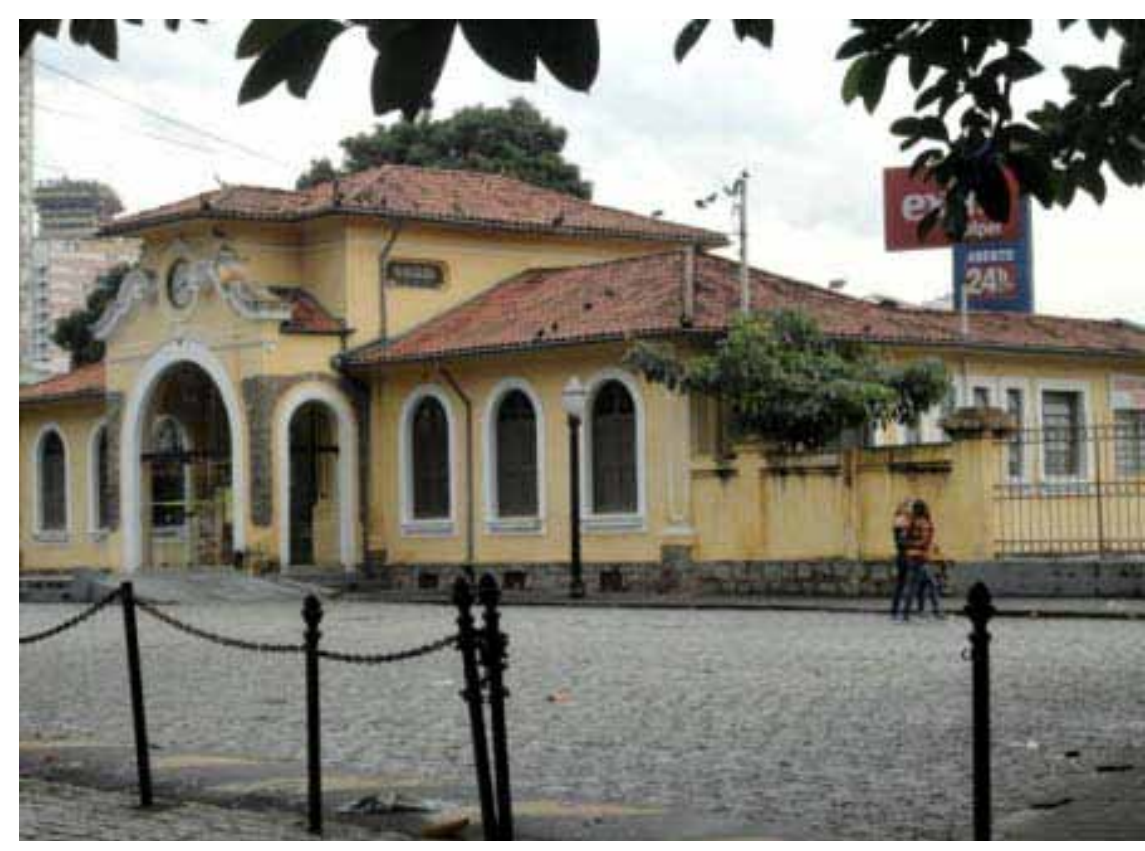

Figura 3 - Faixada da Estação da Cidadania e Cultura (Fonte: Maira Begalli em 10/07/2012).

A construção da sede do Projeto Parcel foi patrocinada pela Petrobras (figura 4), em 2008, quando a área foi concedida pelo prefeito em exercício João Paulo Tavares Papa (2005 - 2008), quando considerou positiva a proposta da ONG realizar projetos socioambientais para a área continental. Atualmente aguarda o resultando do pedido de posse definitiva da área. Encontra-se fora do perímetro urbano, mas possui fácil acesso a transporte público (ponto de ônibus intermunicipal na frente da sede). Seu entorno agrega bairros de comunidades tradicionais, como Quilombo e Ilha Diana.

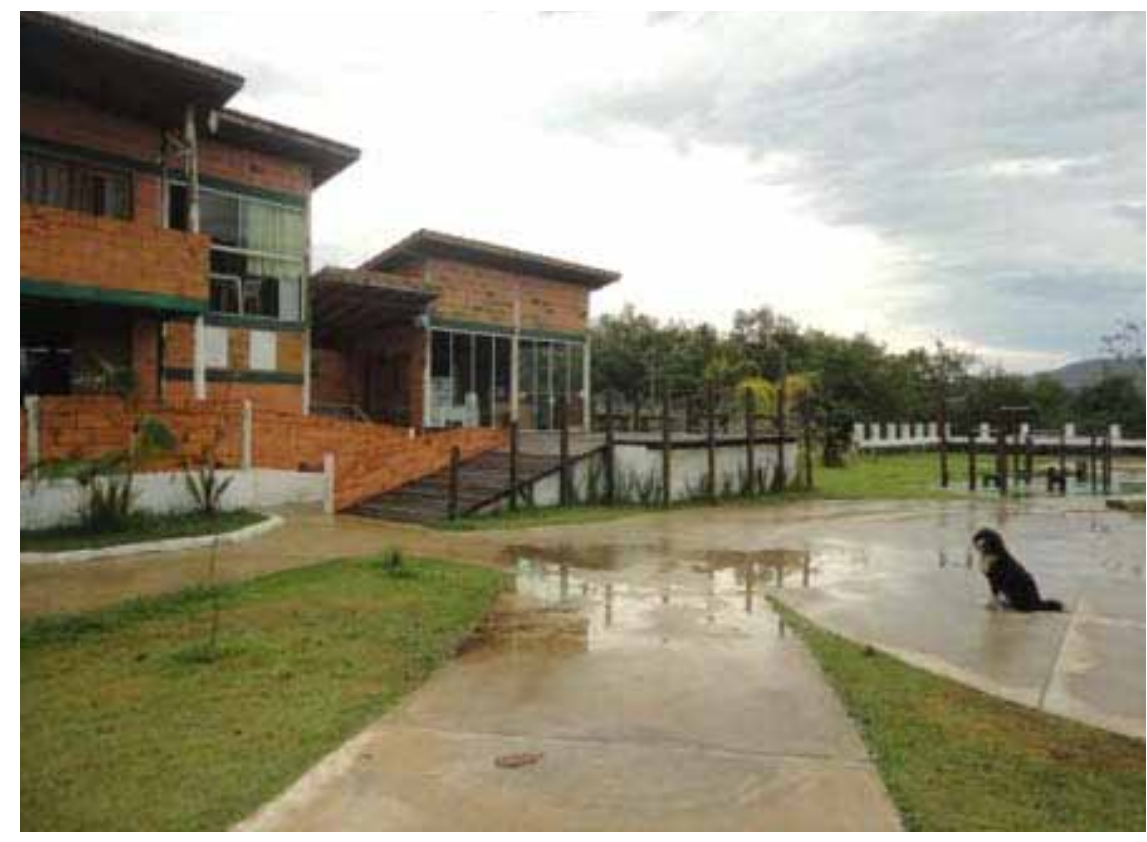

Figura 4 - Sede do Projeto Parcel (Fonte: Maira Begalli em 12/07/2012). 
O Ponto de Cultura Estação da Cidadania e Cultura possui boa infraestrutura, com sanitários, água, energia elétrica, internet e duas salas de aulas amplas, além de um auditório externo, hoje subutilizado (figura 5). Na época da pesquisa, possuía convênio de três anos (2009-2012), estabelecido por meio do Edital de Pontos de Cultura da Secretaria de Cultura do Estado de São Paulo (SEC), através do qual recebia o valor de R\$ 60 mil anuais.

O Projeto Parcel agrega boa infraestrutura, com internet, sanitários, água e luz. Como a Estação da Cidadania e Cultura, na época da pesquisa contava com um convênio semelhante ao da SEC, recebendo o valor de $\mathrm{R} \$ 60$ mil aunais, entre os anos de 2009 e 2012. Também recebe auxílio mensal da Prefeitura Municipal de Santos, com subsídios para água, energia elétrica e internet. Foi contemplado no edital "Sala Verde" (figura 6), na gestão da Ministra do Meio Ambiente Marina Silva (2003-2008), recebendo amplo acervo bibliográfico sobre temáticas ambientais. Atualmente trabalha com projetos de artesanato, educação ambiental e gastronomia regional. Não possui oficinas ou ações direcionadas à apropriação crítica de tecnologias, seja para o uso de ferramentas audiovisuais (como edição de áudio, vídeos e imagens), redes sociais (blogs, plataformas de publicação de conteúdo), assim como aplicações em hardware e softwares livres.

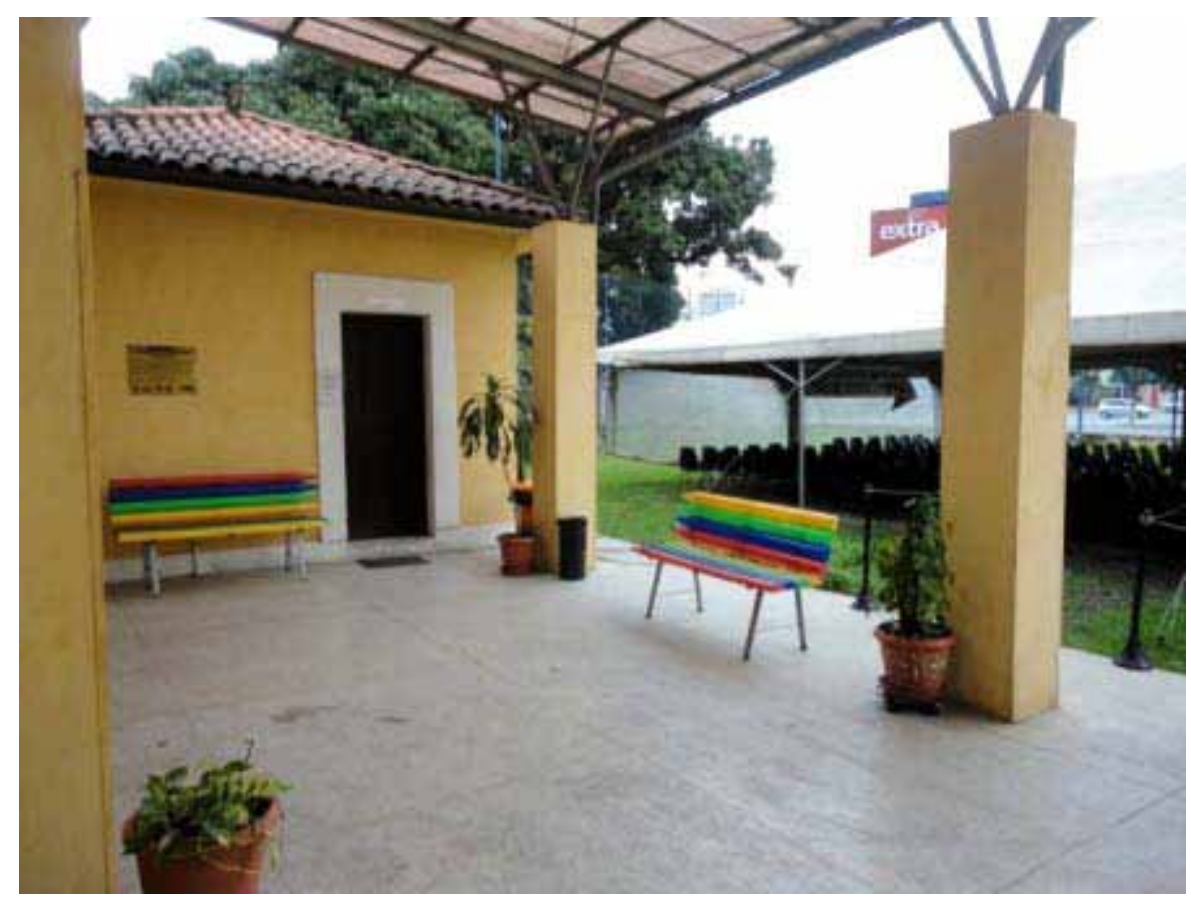

Figura 5 - Instalações da Estação da Cidadania (Fonte: Maira Begalli em 10/07/2012). 


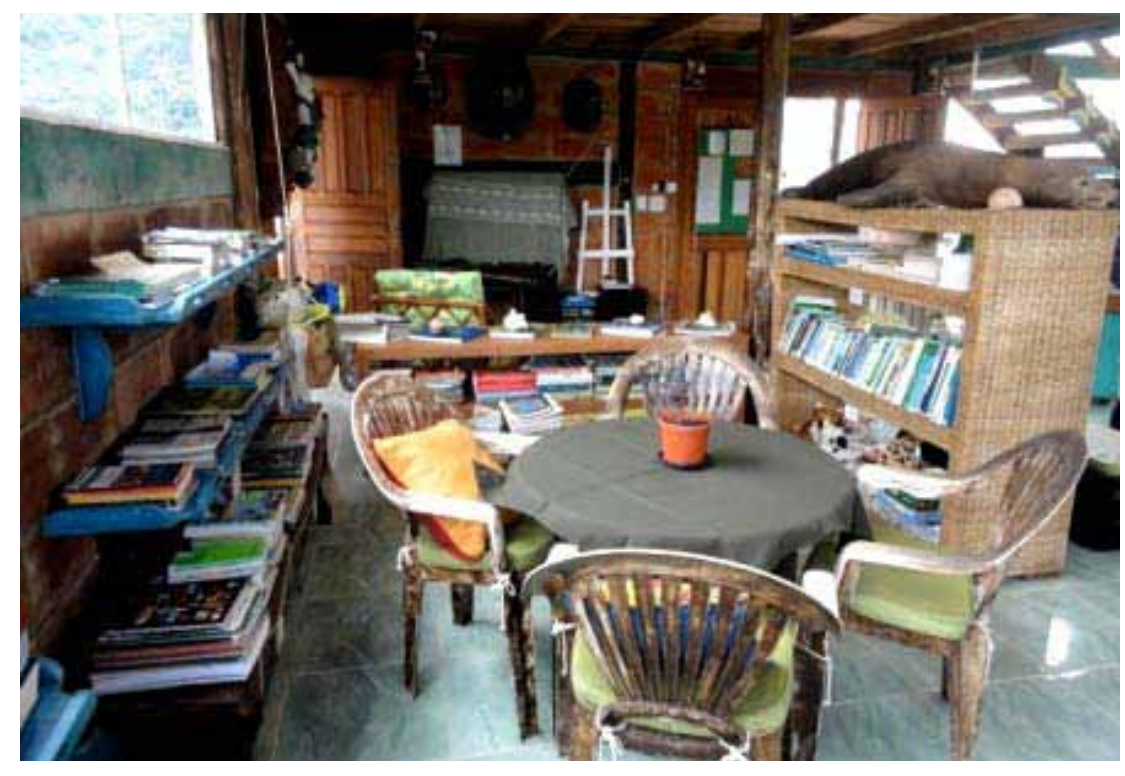

Figura 6 - "Sala Verde" do Projeto Parcel (Fonte: Maira Begalli em 12/07/2012).

\section{CONSIDERAÇÕES FINAIS}

A apropriação crítica de tecnologias tem possibilitado o desenvolvimento de narrativas e ações diversificadas para populações humanas que durante muito tempo permaneceram marginalizadas, devido aos riscos e incertezas ecológicas e econômicas presentes em muitas regiões consideradas como descentralizadas. Assim ao invés de elaborarem produtos bem definidos e com ótimo acabamento, esses indivíduos desenvolvem ações contínuas de documentação e reflexão utilizando diferentes formatos, canais e mídias, como: áudio, vídeo, fotografia e mapeamento (BRUNET \& FREIRE, 2011). Uma forma de co-manejo dos recursos socioambientais baseado em processos de aprendizagem experimental e colaborativa, que busca diminuir a situação de vulnerabilidade socioambiental presente em muitas dessas localidades.

Os dois Pontos de Cultura avaliados, o Projeto Parcel e a Estação da Cultura e Cidadania apresentaram potencial para o desenvolvimento de laboratórios experimentais, como células de co-manejo para o subsídio da relação do ser humano, com a ecologia, a cultura de suas localidades e as diferentes trocas ecológicas-econômicas de onde estão inseridos (Santos ilha e Santos continente). Entretanto, para que tal fato ocorra torna-se necessário a incorporação do co-manejo não apenas como objetivo final, mas no processo do desenvolvimento de um ambiente que estimule a reflexão sobre o contexto sócio-cultural e incorpore a visão da cultura como ecossistema, contemplando: infraestrutura material, recursos humanos, simbólicos e imateriais, como metodologias e processos de trabalho, documentação, redes de confiança, alianças e cumplicidades. 


\section{REFERÊNCIAS BIBLIOGRÁFICAS}

AFONSO, C. M. 1999. Uso e Ocupação do Solo na Zona Costeira do Estado de São Paulo: Uma Análise Ambiental. São Paulo: Annablume: FAPESP. 1 ed, 186 p.

BEGOSSI, A. 1993. Ecologia humana: um enfoque as relações homem-ambiente. Interciência, 18(3): 121-132.

BRASIL. 2005. Portaria número 82, de 18 de maio de 2005. Ministério da Cultura. Disponível em<http://www.in.gov.br/imprensa/visualiza/index.jspdata=23/05/2005\&jor nal=1\&pagina=14\&totalArquivos=64>. Acesso em 01 de janeiro de 2013.

BRASIL. 2012. Ministério da Cultura. Pontos de Cultura de Santos. IN: Catálogo da Rede de Pontos de Cultura do Estado de São Paulo - 2010 a 2012. São Paulo: Ministério da Cultura/ Secretaria de Estado da Cultura, p. 96-97.

BRUNET, K.; FREIRE, J. 2011. Data Visualization and eco-media content. Media Art produced at Digital Narratives workshops. Trabalho apresentado no 17th International Simposium on Electronic Art. ISEA 2011: Istambul, 7p. Disponível em <http:// karlabru.net/site/wp-content/uploads/2011/05/datavisualization_ISEA_final.pdf>. Acesso em 20 de março de 2013.

FONSECA, Felipe. 2012. Postura Experimental. IN: Archivo Vivo. Disponível em: $<$ http://arquivovivo.org.br/archives/artwork/redelabs/postura-experimental> Acesso em 20 de julho de 2012.

GUITIÉRREZ, Nicolás L.; HILBORN, Ray; DEFEO, Omar. 2011. Leadership, social capital and incentives promote successful fisheries. Nature, 470: 386-389. Disponível em <doi:10.1038/nature09689> Acesso em 10 de novembro de 2012.

HAND, E. 2010. Citizen Science: People power. Nature, 466(7307): 685-687.

KORMONDY, E. J.; BROWN, D. E. 2002. Ecologia Humana. São Paulo: Atheneu, 503 p.

OPEN STREET MAP. 2012. Disponível em <http://openstreetmap.org>. Acesso em 10 de agosto de 2012.

SANTOS. 2012. Website da Prefeitura Municipal de Santos. Prefeitura Municipal de Santos. Disponível em <http://www.santos.sp.gov.br>. Acesso em 20 de agosto de 2012. 
SANTOS. 1999. Lei Complementar número 359, de 25 de novembro de 1999. Câmara Municipal de Santos. Disponível em <http://www.camarasantos.sp.gov.br>. Acesso em 01 de setembro de 2012.

TURINO, Célio. 2009. Ponto de Cultura - O Brasil de Baixo para Cima. São Paulo: Editora Anita Garibaldi, 256p.

VIETLER, Renate B. 2002. Métodos Antropológicos como Ferramenta para Estudos em Etnobiologia e Etnoecologia. IN: AMOROZO, Maria C. de M.; MING, Lin C.; da SILVA, Sandra M. P.. Métodos de Coleta e Análise de Dados em Etnobiologia, Etnoecologia e Disciplinas Correlatas. Anais: Rio Claro: UNESP/CNPq, p. 12-18.

WOHLSEN, M. 2011. Biopunk: DIY Scientists Hack the Software of Life. Inglaterra:Penguin Group, 240 p. 